\title{
PERBANDINGAN KESEJAHTERAAN ANTARA PENGUSAHA DAN PEGAWAI PERSPEKTIF MAQASHID SYARIAH DI KELURAHAN KEJAWAN PUTIH TAMBAK SURABAYA
}

\author{
Khea Miyagi \\ Mahasiswa Program Studi S-1 Ekonomi Islam - Fakultas Ekonomi dan Bisnis - Universitas \\ Airlangga \\ Muhammad Nafik H.R. \\ Departemen Ekonomi Syariah - Fakultas Ekonomi dan Bisnis - Universitas Airlangga \\ Email: manhard999@yahoo.com
}

\begin{abstract}
This study aims to identify and analyze Comparison Between Employers and Employees Welfare maqashid Shariah Perspective in the Village Kejawan Putih Tambak Surabaya. That is the basis of interview questions to determine the welfare comparison between employers and employees in terms of five aspects, namely, religion, life, intellect, lineage and property.

This study used a qualitative approach with ethnographic strategy. Data was collected through interviews and direct observation to study the object. The analysis technique used is descriptive qualitative analysis narrate the results of interviews and direct observation.

The results of this study is that there is little difference between employers and employee welfare. The welfare of employers better meet the criteria Maqashid Shariah Perspective. The employers have more time to gather with family, having time to pray in the mosque, pay more attention to their health and have more social activities than employees. While employees have limited time to gather with family, can not pray in a timely manner, rarely have time to socialize and do not have time for a workout. Therefore employers mental welfare is better than employees.
\end{abstract}

Keywords: Employers, Employees, Welfare, Maqashid Sharia

\section{PENDAHULUAN}

\section{A. Latar Belakang}

Allah SWT menciptakan bumi beserta seluruh isinya agar hamba-Nya senantiasa menyembah kepada Allah SWT. Salah satu cara menyembah-Nya adalah dengan bekerja. Dalam ajaran agama Islam bekerja merupakan ibadah, dimana hakikat hukum ibadah adalah wajib. Sehingga dapat ditarik kesimpulan bahwa bekerja adalah kewajiban bagi umat muslim.

Bagi seorang muslim, makna bekerja berarti niat yang kuat untuk mewujudkan hasil kerja yang optimal atau outstanding performance, bukan hanya memberikan nilai rata-rata. Ada semacam "nyala api dalam diriku (burning in my heart)" yang terus mengetuk-ngetuk dirinya seraya menyuarakan sebuah bisikan. "Sungguh tidak pantas bagi seorang wakil Allah hanya bekerja asal-asalan, apalagi terpuruk dalam kemalasan dan kebodohan". Tasmara (2000:8)

Pandangan agama Islam, seorang yang bersusah-payah mencari rezeki yang halal dan hasilnya digunakan sepenuhnya di jalan Allah disamakan derajatnya dengan para mujahid yang berperang di jalan Allah. Islam mewajibkan setiap 
umatnya bekerja untuk mencari rezeki agar menghasilkan pendapatan untuk memenuhi kebutuhan hidupnya. Allah telah memberi banyak kenikmatan dan kemudahan di dunia ini untuk umatnya mencari rezeki yang halal. Islam memerintahkan umatnya agar mencari rezeki yang halal karena pekerjaan itu adalah bagai memelihara kehormatan dirinya. Rasulullah SAW memberikan pelajaran menarik tentang pentingnya bekerja. Dalam Islam bekerja bukan sekadar memenuhi kebutuhan hidup, tapi juga untuk memelihara harga diri dan martabat kemanusiaan yang seharusnya dijunjung tinggi. Karenanya, bekerja dalam Islam menempati posisi yang teramat mulia. Islam sangat menghargai orang yang bekerja dengan tangannya sendiri.

Bekerja memiliki kaitannya dengan martabat manusia. Seorang yang telah bekerja dan bersungguh-sungguh dalam pekerjaannya akan bertambah martabat dan kemuliannya. Sebaliknya, orang yang tidak bekerja atau menganggur, selain kehilangan martabat dan harga diri di hadapan dirinya sendiri, juga di hadapan orang lain. Jatuhnya harkat dan harga diri akan menjerumuskan manusia pada perbuatan hina. Tindakan mengemis merupakan kehinaan, baik dari sisi manusia maupun dari sisi Allah SWT.

Motivasi seseorang untuk bekerja adalah agar mendapatkan penghasilan untuk memenuhi kebutuhan hidup. Menurut teori hirarki kebutuhan Maslow motivasi untuk mendapatkan rasa aman merupakan motivasi yang dominan pada setiap manusia, Termasuk rasa aman dalam hal pendapatan atau kebutuhan untuk mendapatkan keamanan selama hidupnya. Salah satu cara untuk mendapatkan penghasilan adalah menjadi seorang pengusaha. Pengusaha adalah seseorang yang menciptakan sebuah usaha, mempekerjakan orang lain untuk bekerja dan mengendalikan sistem usaha yang diciptakan.

Kesejahteraan pada umumnya apabila tercapainya perasaan aman, damai serta bahagia. Kesejahteraan amat berkaitan dengan pencapaian yang khusus, seperti terpenuhi segala kebutuhan hidup dan berkaitan dengan keadaan yang lebih umum seperti kesenangan hidup maupun dalam kehidupan berumah tangga. Sedangkan kesejahteraan menurut pandangan Islam tidak hanya dinilai dengan ukuran materi saja tetapi juga dinilai dengan ukuran non material, seperti contohnya: terpenuhimya kebutuhan spiritual, terpeliharanya nilai-nilai moral dan terwujudnya keharmonisan sosial. Dalam Islam, dikatakan sejahtera apabila terpenuhinya dua kriteria. Pertama, terpenuhinya kebutuhan pokok setiap individu baik sandang, pangan, papan, pendidikan serta kesehatannya. Kedua, terjaga dan terlindunginya agama, jiwa, akal, keturunan dan harta. Manusia harus 
menjaga dan menerapkan lima hal tersebut menjadi satu kesatuan agar tercapai tujuan akhir sebagai manusia. Kesejahteraan tidak hanya diukur dari segi ekonomi saja melainkan dari segi maqashid syariah. Allah SWT telah menjadikan agama sebagai dinul kamil, agama yang sempurna. Islam telah mengatur seluruh aspek kehidupan dengan demikian, dapat dikatakan bahwa kandungan maqashid syariah adalah kemaslahatan umat bersama.

Kejawan putih tambak tadinya adalah kawasan pertambakan yang berada di sebelah timur Surabaya. Saat ini perkembangan kawasan kejawan putih tambak cukup pesat, sesuai dengan namanya kawasan ini dulunya di dominasi dengan areal tambak dan penduduk yang bermata pencaharian sebagai nelayan. Seiring dengan berjalannya waktu kawasan ini menjadi kawasan yang diminati para pemilik modal. Lembaga pendidikan Islam Hidayatullah dan Al Uswah adalah contoh lembaga pendidikan yang berada di kawasan ini.Selain lembaga pendidikan terdapat pula perumahan elite Pakuwon City yang menyulap tambak menjadi perumahan yang modern dan ramai. Sesuai dengan latar belakang yang telah dipaparkan pada paragraph-paragraf sebelumnya, penelitian ini bertujuan untuk mengetahui bagaimana perbandingan kesejahteraan perspektif maqashid syariah antara pengusaha dan pegawai di

keluarahan Kejawan Putih Tambak Surabaya.

\section{LANDASAN TEORI DAN PENGEMBANGAN PROPOSISI}

\section{A. Pendapatan}

Allah SWT telah menentukan rezeki masing-masing setiap orang yang satu dan yang lainnya. Allah SWT telah memerintahkan kepada umatnya agar mencari rezeki dengan cara bekerja. Dengan bekerja manusia akan mendapat imbalan berupa gaji atau upah. Dengan adanya pendapatan dari bekerja manusia dapat memenuhi segala kebutuhan hidupnyadi dunia. Sebagai umat muslim yang beriman diwajibkan untuk mencari rezeki di jalan yang sudah Allah tentukan. Jalan yang baik dan di ridhai oleh Allah SWT untuk mendapatkan rezeki yang halal dan barokah.

Bekerja adalah hal yang diwajibkan dalam Islam untuk memenuhi kebutuhan hidup seseorang. Agama Islam mengajarkan bahwa janganlah manusia hidup semata-mata hanya untuk akhirat saja namun agama Islam menganjurkan adanya keseimbangan antara kehidupan di dunia dan kehidupan di akhirat.

(Al-Hajj (22):50 :

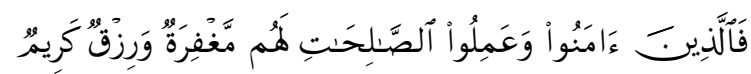


fallażināamanū wa'amilū şşālihāti lahum maghfiratun warizqun karim

"Maka orang-orang yang beriman dan beramal saleh, bagi mereka ampunan dan rezki yang mulia"

Bekerja memiliki kaitannya dengan martabat manusia. Seorang yang telah bekerja dan bersungguh-sungguh dalam pekerjaannya akan bertambah martabat dan kemuliaannya. Sebaliknya, orang yang tidak bekerja atau menganggur, selain kehilangan martabat dan harga diri di hadapan dirinya sendiri, juga di hadapan orang lain. Jatuhnya harkat dan harga diri akan menjerumuskan manusiapada perbuatan hina. Tindakan mengemis merupakan kehinaan, baik dari sisi manusia maupun dari sisi Allah SWT.

Allah berfirman dalam surat AdzZariyat ayat $56-58$, yaitu :

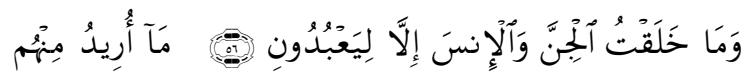

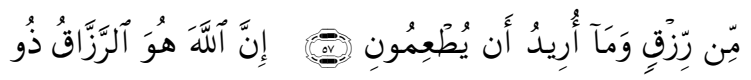

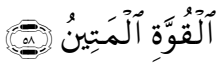

wamaa khalaqte ljinna wal-insa illaa liya'buduunmaa uriidu minhum min rizqin wamaa uriidu an yuth'imuun innallaaha huwa rrazzaaqu dzuu lquwwati Imatiin

"Dan aku tidak menciptakan jin dan manusia melainkan supaya mereka mengabdi kepada-Ku. AkU tidak menghendaki rezki sedikitpun dari mereka dan aku tidak menghendaki supaya mereka memberi-Ku makan.Sesungguhnya Allah Dialah Maha pemberi rezki yang mempunyai kekuatan lagi sangat kokoh."

Penjelasan mengenai ayat diatas ialah sesungguhnya Allah SWT telah memberi tahu kepada manusia bahwa tujuan hidup manusia di dunia hanyalah untuk menyembah-Nya. Allah SWT tidak meminta apapun dari manusia, justru manusialah yang meminta rezeki, kekayaan dan kemewahan dunia kepada-Nya. Oleh karena itu mintalah rezeki sebanyakbanyaknya kepada Allah SWT dengan tidak lupa untuk senantiasa menyembah-Nya. Adapun pada surat Thaaha (20) ayat 130132, Allah berfirman mengenai rezeki, yaitu :

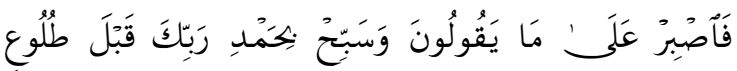

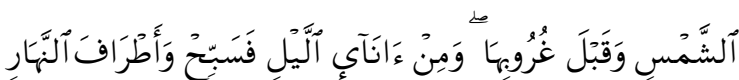
لَعَلَّكَ تَرَضَنْ

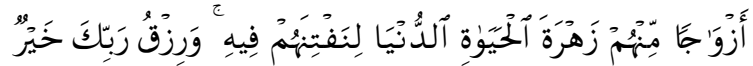

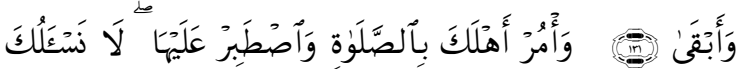

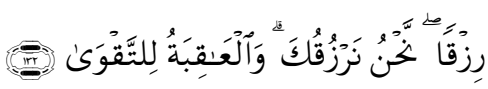

fashbir 'alaa maa yaquuluuna wasabbih bihamdi rabbika qabla thuluu'i sysyamsi waqabla ghuruubihaa wamin aanaa-illayli 
fasabbih wa-athraafa nnahaari la'allaka tardaa walaa tamuddanna 'aynayka ilaa maa matta'naa bihi azwaajan minhum zahrata Ihayaati ddunyaa linaftinahum fiihi warizqu rabbika khayrun wa-abqaa wa'mur ahlaka bishshalaati wasthabir 'alayhaa laa nas-aluka rizqan nahnu narzuquka wal'aaqibatu littaqwaa

"Maka sabarlah kamu atas apa yang mereka katakan, dan bertasbihlah dengan memuji Tuhanmu, sebelum terbit matahari dan sebelum terbenamnya dan bertasbih pulalah pada waktu-waktu di malam hari dan pada waktu-waktu di siang hari, supaya kamu merasa senang, Dan janganlah kamu tujukan kedua matamu kepada apa yang telah Kami berikan kepada golongan-golongan dari mereka, sebagai bunga kehidupan dunia untuk Kami cobai mereka dengannya. dan karunia Tuhan kamu adalah lebih baik dan lebih kekal. Dan perintahkanlah kepada keluargamu mendirikan shalat dan bersabarlah kamu dalam mengerjakannya. Kami tidak meminta rezki kepadamu, kamilah yang memberi rezki kepadamu.dan akibat (yang baik) itu adalah bagi orang yang bertakwa."

Dari ketiga ayat diatas, menerangkan mengenai konsep beribadah dan konsep rezeki.Rezeki sesungguhnya telah dicatat oleh Allah SWT di lauhil mahfuuzh. Lauhil mahfuuzh adalah sebuah lembaran yang di dalamnya Allah SWT telah mencatat semua peristiwa yang akan terjadi, dimulai dari penciptaan manusia hingga hari pembalasan.

Ketiga ayat diatas menjelaskan Islam mewajibkan setiap umatnya bekerja untuk mencari rezeki agar menghasilkan pendapatan untuk memenuhi kebutuhan hidupnya. Allah telah memberi banyak kenikmatan dan kemudahan di dunia ini untuk umatnya mencari rezeki yang halal. Islam memerintahkan umatnya agar mencari rezeki yang halal karena pekerjaan itu adalah bagaikan memelihara kehormatan dirinya. Adapun cara untuk mendapatkan penghasilan adalah sebagai pengusaha. Pengusaha adalah seseorang yang menciptakan sebuah usaha, mempekerjakan orang lain untuk bekerja dan mengendalikan sistem usaha yang diciptakan. Rasulullah bersabda bahwa:

"Perhatikan olehmu sekalian, sesungguhnya perdagangan itu di dunia ini adalah sembilan dari sepuluh pintu rezeki" (HR Ahmad).

Tetapi untuk mendapatkan penghasilan tidak hanya sebagai pengusaha, menjadi pegawai sebuah perusahaan atau di kantor pemerintahaan pun akan mendapatkan penghasilan yang akan memenuhi kebutuhan hidup dan kebutuhan rasa aman. Hal tersebut akan tercapai jika dalam mencari nafkah dan membelanjakannya sesuai dengan perintah Allah SWT. 


\section{Kesejahteraan}

Pada dasarnya manusia adalah makhluk sosial, baik kita suka atau tidak hampir semua yang kita lakukan dalam kehidupan kita berkaitan dengan orang lain. Kondisi sejahtera (well-being) biasanya menunjuk pada istilah kesejahteran sosial (social welfare) sebagai kondisi terpenuhinya kebutuhan material dan non material. Menurut Midgley (2000:xi) mendefinisikan kesejahteraan sosial sebagai "..a condition or state of human well-being." Kondisi sejahtera terjadi manakala kehidupan manusia aman dan bahagia karena kebutuhan dasar gizi, kesehatan, pendidikan, sosial, tempat tinggal, dan pendapatan dapat terpenuhi. Serta manusia memperoleh perlindungan dari resiko-resiko utama yang mengancam kehidupannya.

Sejahtera dapat diartikan nasib yang baik, kesehatan, kebahagiaan, dan kemakmuran dalam konteks bermasyarakat, kesejahteraan diartikan sebagai bantuan keuangan atau lainnya kepada individu atau keluarga dari organisasi swasta dan negara atau pemerintah dikarenakan kesulitan dalam memenuhi kebutuhan hidupnya. Karena sebagian besar orang memandang dikatakan sejahtera apabila pendapatan keuangannya yang melebihi cukup.
Pandangan dunia mengenai kesejahteraan, dimana setiap manusia bertujuan mencapai kesejahteraan dalam hidupnya, namun manusia memiliki pengertian yang berbeda-beda tentang kesejahteraan. Dalam ekonomi konvensional dapat disimpulkan bahwa tujuan manusia memenuhi kebutuhannya atas barang dan jasa adalah untuk mencapai kesejahteraan (well being). Manusia menginginkan kebahagiaan dan kesejahteraan dalam hidupnya dan untuk inilah manusia berjuang dengan cara bekerja untuk mencapainya.

Pada dasarnya kesejahteraan merupakan tujuan dasar setiap individu. Widiastuti (2008:39) Dalam pemikian Islam, Islam menginginkan setiap individu untuk memperhatikan kesejahteraanya. Oleh karena itu yang mendasari kaum muslimin dalam beraktivitas adalah perintah agama untuk mencapai kesejahteraan yang berdimensi dunia akhirat. Semua aktivitas yang menuju arah kesejahteraan umat (maslahah) disebut dengan kebutuhan, dan kebutuhan ini harus dipenuhi.

Tolak ukur untuk melihat kesejahteraan suatu masyarakat atau bangsa sering dipakai konsep GNP per kapita, namun belakangan ini dikembangkan lagi tolak ukur yang lebih kompleks yaitu Physical Quality of Life Index (PQLI) dan Human Development Index (HDI). Menurut Morris dalam Todaro (2000) Indeks Kualitas Hidup Secara Fisik (PQLI, 
Physical Quality of Life Index) atau indeks gabungan terdiri atas tiga unsur pokok, yakni tingkat harapan hidup seseorang selepas usia satu tahun (life expectancy at age 1), tingkat kematian bayi(infant mortality), dan tingkat melek huruf (literacy). Masing-masing indikator itu mengukur kinerja pembangunan atau kesejahteraan masyarakat suatu negara berdasarkan skala dari 1 hingga 100. Angka 1 melambangkan kinerja terburuk, sedangkan kinerja terbaik akan diberi angka 100. Untuk harapan hidup pada usia satu tahun, angka 100 akan diberikan jika rata-rata usia harapan hidup penduduk mencapai 77 tahun, sedangkan angka 1 diberikan jika rata-rata usia harapan penduduk mencapai 28 tahun.

Kaitannya dengan tingkat kematian bayi, batas kinerja yang dianggap paling tinggi akan mendapat nilai 100 adalah apabila terjadi tingkat kematian itu 9 per 1.000 kelahiran, sedangkan angka 1 akan diberikan apabila tingkat kematian bayi 229 per 1.000 kelahiran. Tingkat melek huruf, diukur langsung persentasenya dari angka 1 sampai 100. Indeks gabungannya diperoleh dengan cara yang sederhana, yakni menjumlahkan ketiga skor tersebut lantas dibagi dua.

\section{B. Kesejahteraan Perspektif Islam}

Ekonomi Islam merupakan ilmu yang bertujuan untuk tercapainya kemaslahatan umat dengan menghendaki terwujudnya pembagian pendapatan yang adil sehingga dapat memenuhi kebutuhan setiap individu. Pada dasarnya setiap individu berhak mendapatkan hak dan kewajibannya sesuai dengan apa yang telah ia kerjakan. Dan Islam melarang semua kegiatan yang buruk dan berdampak pada kerusakan.

Shihab (1996:407-408) kebutuhan biasa diartikan sebagai hasrat manusia yang perlu dipenuhi atau dipuaskan. Kebutuhan bermacam-macam dan bertingkat-tingkat, namun secara umum dapat dibagi dalam tiga jenis sesuai dengan tingkat kepentingannya. Primer (dharuriyat), sekunder (hajiyat), dan tersier (kamaliyat). Jenis kebutuhan kedua dan ketiga sangat beraneka ragam, dan dapat berbeda-beda dari seorang dengan lainnya, namun kebutuhan primer sejak dahulu hingga kini dapat dikatakan sama dan telah dirumuskan oleh pakar sebagai kebutuhan sandang, pangan, dan papan.

Al-Qur'an secara tegas menyebutkan ketiga macam kebutuhan primer itu dan mengingatkan manusia pertama tentang keharusan pemenuhannya sebelum manusia pertama itu menginjakkan kakinya di bumi. Ketika Adam dan Hawa masih berada di Surga, Allah mengingatkan mereka berdua dalam surah Taha [20] 117-119: 


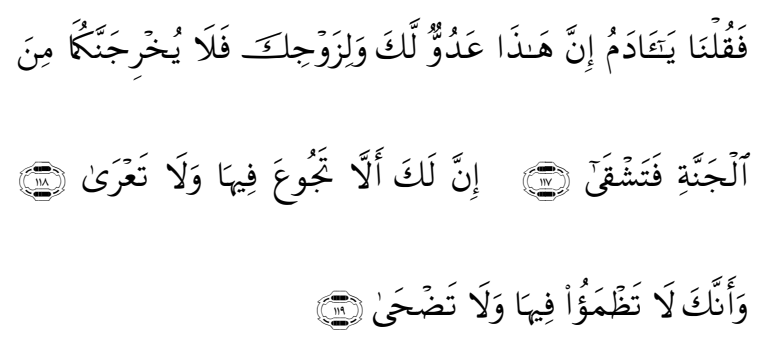

faqulnā yā ādamu inna hāżā 'aduwwun laka walizawjika falā yukhrijannakumā mina ljannati fatasyqā. inna lakallā tajū'a fihā walā ta'rā

"Maka Kami berkata: "Hai Adam, Sesungguhnya ini (iblis) adalah musuh bagimu dan bagi isterimu, Maka sekali-kali janganlah sampai ia mengeluarkan kamu berdua dari surga, yang menyebabkan kamu menjadi celaka. Sesungguhnya kamu tidak akan kelaparan di dalamnya dan tidak akan telanjang, Dan Sesungguhnya kamu tidak akan merasa dahaga dan tidak (pula) akan ditimpa panas matahari di dalamnya"."

Yang dimaksud dengan bersusah payah adalah bekerja untuk memenuhi kebutuhan mereka yang di dunia tidak diperoleh tanpa kerja tetapi di surga telah di sediakan yaitu pangan atau dalam bahasa ayat di atas "tidak lapar dan tidak dahaga". Sandang dilukiskan dengan "tidak telanjang", sedangkan papan diisyaratkan oleh kalimat "tidak disengat matahari". Sementara ulama menganalisis mengapa peringatan ini ditujukan kepada mereka berdua selaku suami-istri, tetapi pernyataan bersusah payah dikemukakan dalam bentuk tunggal yaitu ditujukan kepada suami (Adam) saja. Jawabannya menurut mereka adalah, karena kebutuhan sandang, pangan, dan papan, merupakan kebutuhan pria dan wanita (suami-istri), tetapi kewajiban bersusah payah mencarainya berada di pundak suami sehingga merupakan kewajiban suami untuk mengikhtiarkannya.

Menurut Manzoor (2000) dalam Diola (2011:33) beberapa dasar utama dari kebijakan kesejahteraan ekonomi syariah antara lain, sebagai berikut:

1. Semua kekuasan adalah milik Allah dan Dia-lah pemilik sesungguhnya atas segalanya yang ada, seperti yang tersirat pada surat Ar-Rum ayat 40 :

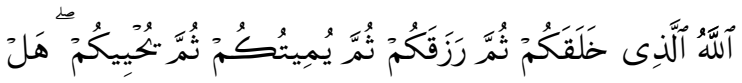

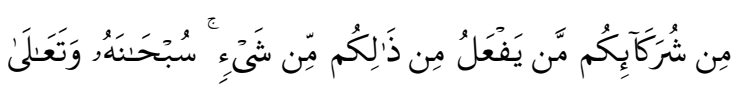
عَمَّا يُشَرِكُونَ

Al-laahul lażi khalaqakum śum-ma razaqakum śum-ma yumitukum śum-ma yuhyikum hal min syurakaa-ikum may yaf'alu min żaalikum min syai subhanahū wa ta'aalaa 'am-maa yusyrikun

"Allah-lah yang menciptakan kamu, kemudian memberimu rezki, kemudian 
mematikanmu,

kemudian

menghidupkanmu (kembali). Adakah di antara yang kamu sekutukan dengan Allah itu yang dapat berbuat sesuatu dari yang demikian itu? Maha sucilah Dia dan Maha Tinggi dari apa yang mereka persekutukan."

2. Manusia ditunjuk-Nya sebagai Khalifah (pemimpin) di bumi tapi bukanlah pemilik sesungguhnya atas apa yang telah diberikan-Nya di dunia ini, hal ini sesuai dengan surat Al-Baqarah ayat 107.

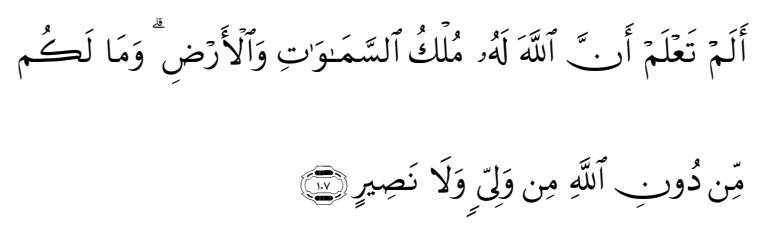

Alam ta'lam 'an-nal-laaha lahū mulkussamaawaati wal "ardi wa maa lakum min dūnil-laahi miw-waliy-yiw wa laa naşīr

"Tiadakah kamu mengetahui bahwa kerajaan langit dan bumi adalah kepunyaan Allah?dan tiada bagimu selain Allah seorang pelindung maupun seorang penolong."

3. Hal-hal duniawi yang telah dimiliki atau diperoleh manusia adalah karunia dari Allah. Oleh karena itu, orang yang kurang beruntung(dalam hal ekonomi) juga harus membagikan hartanya.

4. Kekayaan dapat diperoleh tanpa melanggar norma-norma Islam.
5. Kekayaan harus selalu disisakan dalam penggunaannya, dalam beberapa hal menyimpan harta dan sumber daya tidak bermanfaat.

6. Larangan terhadap segala bentuk pemerasan ekonomi. Seperti contoh, Larangan terhadap bunga. Menghilangkan pemerasan dari struktur kevangan ekonomi.

7. Menekankan untuk menghilangan konflik atau perselisihan antar golongan dengan cara menghilangkan perbedaan keadaan ekonomi tiap individu.

8. Mewariskan kekeyaan dengan cara membagikan harta setelah kematian kepada ahli warisnya.

9. Kewajiban memberi dan menyumbangkan sebagian dari harta pada tiap individu untuk dibagikan kepada fakir miskin.

10. Keadilan ada dalam aturan Islam dan hati.

11. Tujuan negara harus menegakkan keadilan dan menghilangkan kedzalaman dan penindasan.

12. Tujuan negara harus menggunakan semua sumber daya dan kemampuan rakyatnya untuk menegakkan syariah Islam yang baik dan pantas untuk dilaksanakan. Dan semua berbahaya dan jahat harus ditinggalkan.

13. Semua warga negara di negara Islam harus mempunyai hak yang sama. 
14. Kepemerintahan harus berdasarkan atas kepercayaan dan semua urusan negara harus ditngani oleh orang-orang yang bisa dipercaya.

15. Keadilan dan efisiensi pertimbangan dalam Islam adalah sebuah hasil dari dasar-dasar aktivitas ekonomi pemerintahan pada umumnya. Hal-hal mengenai kepemilikan dan pnggunaan sumber daya, dan penyaluran dari hasil akhir.

16. Pedoman utama bagi kegiatan manusia dalam bidang ekonomi diberikan dalam surat An-Nahl ayat 90:

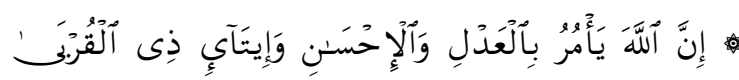
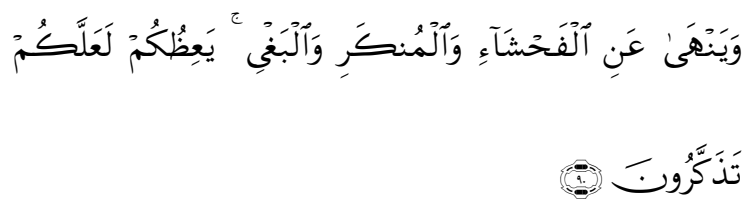

In-nal-laaha ya' muru bil adli wal ihsaani ìtaa-i żal qurbaa wa yanhaa 'anil fahsyaa-i wal munkari wal baghyi ya'izhukum la'allakum tażak-karūn

"Sesungguhnya Allah menyuruh (kamu) Berlaku adil dan berbuat kebajikan, memberi kepada kaum kerabat, dan Allah melarang dari perbuatan keji, kemungkaran dan permusuhan. Dia memberi pengajaran kepadamu agar kamu dapat mengambil pelajaran."
Ekonomi kesejahteraan konvensional hanya menekankan pada kesejahteraan material saja, tanpa adanya kesejahteraan spiritual dan moral. Tujuan utama kesejahteraan ekonomi Islam ialah kesejahteraan yang menyeluruh, seperti kesejahteraan material, kesejahteraan spiritual dan moral. Konsep ekonomi kesejahteraan syariah bukan saja berdasarkan manifestasi nilai ekonomi, tetapi juga nilai moral dan spiritual, nilai sosial dan nilai politik Islami. Dengan demikian ekonomi kesejahteraan syariah mempunyai konsep lebih komprehensif.

\section{Maqashid Syariah}

Menurut As-Shatibi, maqashid syariah terpenuhinya maslahah dasar bagi kehidupan manusia terdiri dari lima hal, yaitu agama (dien), jiwa (nafs), intelektual ('aql), keluarga dan keturunan (nasl), dan material (mal). Kelimanya merupakan kebutuhan mutlak yang harus dipenuhi manusia agar dapat hidup bahagia di dunia dan di akhirat. Jika salah satu dari komponen tersebut tidak terpenuhi, maka kebahagiaan hidup juga tidak akan tercapai dengan sempurna (P3El,2008:5-6).

$$
\text { Sedangkan menurut Ghazali, }
$$
maqashid syariah merupakan bagian dari fungsi kesejahteraan sosial dalam kerangka hierarki utilitas individu dan sosial yang meliputi kebutuhan (dharuriyyat), kesenangan atau kenyamanan (hajiyyat), dan kemewahan (tahsiniyyat) (Karim, 
2007:62) yang kelimanya tersebut diatas tidak terlepas dari pemeliharaan lima fungsi dasar kebutuhan manusia dalam mencapai maslahah.

Riyandono (2009) menyatakan bahwa kebutuhan manusia dibedakan menjadi 3 kebutuhan yaitu;

1. Kebutuhan Primer (dharuriyyat)

Tabel 1.

Hirarki Kebutuhan Al Dhururiyyah

\begin{tabular}{|rl|}
\hline 1. & Agama (Ad din) \\
\hline 2. & Jiwa (An Nafs) \\
\hline 3. & Akal (Al'aql) \\
\hline 4. & Keturunan (An Nasl) \\
\hline 5. & Harta (Al Maal) \\
\hline
\end{tabular}

2. Kebutuhan Skunder (Al Hajiyyah)

3. Kebutuhan Tersier (At Tahsiniyyah)

\section{HASIL PENELITIAN DAN PEMBAHASAN}

Hasil penelitian pada beberapa pengusaha dan pegawai mengenai kesejahteraan yang dilihat dari segi maqashid syariah. Aspek yang pertama adalah agama. Aspek ini dilihat dari segi rukun Islam. Menunjukkan beberapa perbedaan diantaranya dari segi pengusaha. Dari aspek maqashid syariah yang pertama informan yang bekerja sebagai pengusaha memiliki beberapa perbedaan, diantaranya adalah informan 3 dan informan 4. Informan 3 dan informan 4 tidak pernah buka bersama dengan anak yatim tetapi hanya memberikan takjil ke masjid. Informan 3 dan Informan 4 juga belum memiliki tabungan untuk naik haji. tSedangkan dalam meningkatkan keimanan setiap informan memiliki jawaban yang berbeda-beda. Ada yang berusaha mengkhatamkan Al-Qur'an setiap 3 bulan sekali, ada yang pergi ke pengajian dan kajian setiap minggu, ada yang selalu melakukan perintah Allah SWT dengan taat, dan ada yang mendidik keluarga terutama anak-anak dengan prinsip agama yang kuat. Dalam melaksanakan sholat wajib informan berusaha untuk mengerjakan dengan tepat waktu dan semua informan berusaha selalu istiqomah untuk menjalankan sholat sunnah. Semua informan menyalurkan zakat, ada yang ke lembaga zakat ada yang langsung menyalurkan zakatnya secara personal sesuai dengan ketentuan nisab masingmasing. Untuk informan 1, dan informan 2 memiliki agenda rutin untuk berbuka bersama anak yatim sedangkan informan 5 tidak pernah berbuka bersama dengan anak yatim tetapi ketiga informan ini telah melaksanakan rukun Islam yang terakhir yaitu naik haji.

Aspek maqashid syariah yang kedua adalah jiwa. Pada aspek ini menunjukkan bahwa beberapa informan tidak memperhatikan kesehatannya ada yang 
tidak suka olahraga ada pula yang tidak memperhatikan menu makanan yang sehat. Tetapi hampir semua informan menjaga kebersihannya dan mewajibkan anak laki-lakinya untuk sholat berjama'ah ke masjid.

Aspek maqashid syariah yang ke 3 adalah akal. Dalam hal ini informan 1, 2, dan 3 mewajibkan anak-anaknya untuk sekolah di sekolah yang berbasis agama Islam. Menurut pendapat mereka pendidikan agama harus diberikan di lingkungan rumah dan lingkungan sekolah agar pengetahuan tentang agama tidak berkurang sedikitpun. Pengetahuan umum dan pengetahuan agama harus seimbang agar anak memiliki prinsip yang kuat dalam menjalankan hidupnya. Sedangkan untuk informan 4 dan 5 hanya mewajibkan anakanaknya bersekolah di sekolah yang berbasis agama ketika anak-anak mereka masih TK dan SD karena menurut pendapat mereka pendidikan agama cukup diberikan oleh orang tua di rumah dan diberikan sewaktu sekolah dasar agar sewaktu ke jenjang sekolah yang berikutnya anak bisa lebih berfikir secara umum dan luas.

Aspek yang keempat adalah keturunan, dalam menjaga keturunannya semua informan membekali dan mengajarkan kepada anak-anaknya nilainilai prinsip agama Islam agar terciptanya generasi yang lebih baik dari sebelumnya.

Aspek yang terakhir adalah harta dalam hal semua informan mencari nafkah yang halal semata-mata untuk mengharap ridho Allah SWT. Dari pendapatan yang didapat terdapat hak orang lain sehingga wajib untuk di sedekahkan. Beberapa informan ada yang memiliki pengeluaran khusus untuk bersedakah, adapula yang mengeluarkan sedekahnya secara spontan. Kesejahteraan yang diukur dari maqashid syariah dilihat dari segi pegawai. Aspek yang pertama adalah agama. Dilihat dari rukun Islam yang 5. Dalam meningkatkan keimanannya setiap informan memiliki caranya masing-masing. Ada yang bangun pada tengah malam untuk melakukan sholat tahajud, ada yang mengajarkan pada keluarganya untuk selalu menanamkan nilai kebaikan, ada yang selalu mentaati segala perintah-Nya, rutin menghadiri pengajian dan mengaji setiap hari sesudah sholat. Sedangkan dalam melaksanakan sholat wajib semua informan tidak pernah melewatkannya hanya saja terkadang tidak dapat untuk sholat tepat waktu dikarenakan waktu bekerja dan banyaknya pekerjaan. Dalam melakukan sholat sunnah hampir semua informan berusaha untuk selalu istiqomah dalam melaksanakannya. Dalam melaksanakan zakat, informan 6 hanya menyalurkan zakat fitrah dikarenakan informan 6 belum bisa membayar zakat mal yang sesuai dengan nisabnya. Sedangkan untuk informan yang lain menyalurkan zakat mal sesuai dengan nisabnya beberapa ada yang melalui lembaga zakat tetapi lebih 
sering menyalurkan zakatnya secara langsung atau ke masjid. Sedangkan untuk berbuka bersama anak yatim hampir semua informan jarang melakukannya hanya sesekali jika ada acara berbuka bersama anak yatim dengan instansi tempat informan bekerja. Dan untuk rukun Islam yang terakhir informan 6 dan 8 belum mempersiapkan tabungan khusus untuk naik haji, sedangkan informan yang lain sudah menyiapkan baik dari segi materi dan mentalnya untuk menunaikan ibadah haji.

Aspek yang kedua adalah jiwa dalam hal ini ada informan yang tidak memperhatikan kesehatannya dengan jarang berolahraga, tetapi memperhatikan menu makanan sehat, ada pula yang rutin berolah raga dan menjaga pola makanan, dan ada juga yang tidak memperhatikan keduanya dikarenakan kesibukan yang dimiliki masing-masing informan dan kepeduliannya terhadap kesehatan masing-masing. Selain itu informan 9 dan 10 mengaku bahwa karena kesibukan masingmasing mengakibatkan waktu berkumpul dengan keluarga menjadi berkurang.

Aspek yang ketiga adalah akal, dalam memilih pendidikan anak, informan 6 memilih pendidikan anak berdasarkan jarak tempuh anak dari rumah ke sekolah, sedangkan informan 7 dan 9 memilih pendidikan anak yang berbasis agama, dan informan 8 dan 10 tidak mengharuskan anaknya untuk sekolah di sekolah yang berlatar belakang agama. Setiap informan memiliki alasan masing-masing, informan 6 mengutamakan sekolah anak berdasarkan jarak tempuh dari rumah ke sekolah dikarenakan agar tidak mengelvarkan biaya tambahan untuk pengeluaran bensin, informan 7 dan 9 memilih sekolah yang berbasis agama dikarenakan menurut pendapat mereka pendidikan agama sangatlah penting diberikan pada lingkungan anak, seperti di sekolah dan di rumah. Sedangkan informan 8 dan 10 mengatakan bahwa pengetahuan agama cukup dari bimbingan orang tua dirumah, untuk pengetahuan umum bisa di dapatkan dari sekolah karena tidak semua orang tua dapat mengajarkan ilmu pengetahuan umum, jadi seimbang antara pengetahuan umum dan pengetahuan agama untuk anak.

Aspek yang selanjutnya adalah keturunan, setiap keluarga pasti mengharapkan generasi selanjutnya yang lebih baik maka dari itu sebagai kepala keluarga semua informan selalu memberikan pandang hidup dilihat dari sisi agama maupun sisi umum agar seimbang antara dunia dan akhirat. Aspek maqashid syariah yang terakhir adalah harta. Pada aspek ini informan mencari nafkah di jalan yang halal semata-mata untuk membiayai kebutuhan keluarga dan dengan mengharap ridho Allah SWT. Semua informan berpendapat bahwa dari segala rezeki yang di dapat terdapat hak dari 
saudara-saudara muslim sehingga wajib untuk di sedekahkan.

\section{KESIMPULAN DAN SARAN}

\section{A. Simpulan}

Kesamaan antara pengusaha dan pegawai ialah dalam hal keturunan. Para pengusaha dan pegawai senantiasa memberikan arahan-arahan tentang dasardasar agama agar anak-anaknya memiliki prinsip yang kuat dalam menjalankan kehidupan dan memberikan pandanganpandangan hidup supaya menjadikan generasi yang lebih baik.

Hasil penelitian menunjukkan tidak terjadi kesenjangan kesejahteraan dalam hal materi (Al-Maal) antara pengusaha dan pegawai. Dengan demikian pengusaha memiliki kesejahteraan secara kebahagiaan batin lebih baik dibandingkan dengan pegawai.

\section{B. Saran}

1. Bagi pemerintah untuk mendorong para pengusaha agar lebih terpenuhi kesejahteraan lahir dan batinnya untuk menjadi Indonesia yang seutuhnya.

3. Untuk peneliti selanjutnya, penelitian ini dapat di gunakan untuk melakukan penelitian terhadap kesejahteraan perspektif maqashid syariah dengan detail penelitian yang lebih mendalam.

\section{DAFTAR PUSTAKA}

Abdul, Hakim. 2013. Pengaruh Dana Bantuan Langsung Masyarakat Terhadap Penyerapan Tenaga
Kerja dan Perkembangan Usaha Tani Padi Serta Kesejahteraan Kelvarga Petani Kabupaten Kota di Provinsi Nusa Tenggara Barat Dalam Perspektif Islam. Disertasi tidak diterbitkan. Pascasarjana Universitas Airlangga.

Abraham H. Maslow. 1994. Motivasi dan Kepribadian 1. (Teori Motivasi dengan Pendekatan Kebutuhan Manusia). Jakarta. PT. PBP

Al-Qur'an Tafsir dan Terjemahannya. 1978. Bandung: Firma Sumatra Bandung Lembaga Penterjemah dan Tafsir Al-Qur'an.

Badewi, Zaki Ahmad. 1982. Mu'jam Mushthalahâtu al-'Ulûm alljtimâ'iyyah, (Beirut, Maktabah Lubnan : New Impression)

Bakri, Jaya Asyafri. 1996. Konsep Maqashid Syari'ah menurut Syaitibi, Jakarta: Raja Grafindo Persada.

Basrowi. 2011. Kewirausahaan untuk Perguruan Tinggi. Bogor. Ghalia Indonesia

Boediono. 2002. Ekonomi Mikro. BPFE. Yogyakarta

Depdiknas.2008. Kamus Bahasa Indonesia, Jakarta : Pusat Bahasa

Diola, Alfa. 2011. "Peran Baitul Maal Wat Tamwil Dalam Meningkatkan Kesejahteraan Anggota Pada BMT -UGT SIDOGIRI di Kota Surabaya". Skripsi tidak diterbitkan. Fakultas 
Ekonomi dan Bisnis, Universitas Airlangga.

Djamil, Fathurrahman. 1995. Metode ljtihad Majlis Tarjih Muhammadiyah.

Jakarta: Logos Publishing House.

Heryawan, Ahmad. 2009. "Kesejahteraan dan Ukurannya", (Online), (http://ahmadheryawan.blogspot. co.id/kesejahteraan-dan-ukuran,

Diakses pada 1 april 2012)

Karim, Adiwarman. 2007. "Ekonomi Mikro Islami". EdisiKetiga. Jakarta: PT Raja Grafindo Persada.

Michael P. Todoro. 2000. Ekonomi untuk Negara Berkembang. Jakarta. Bumi Aksara

Midgley, James, Martin B. Tracydan Michelle Livermore (ed). The Hanbook of Social Policy. London : Page, halaman xi

Moleong, Lexy J.1988. Metodologi penelitian kualitatif. Edisi Revisi. Bandung : Remaja Rosdakarya

Muhammad Quraish Syihab. Wawasan AlQur'an. Bandung : Mizan, 1996

Nazir, Mohammad. 2003. Metode Penelitian. Jakarta: Ghalia Indonesia.

Undang-Undang Republik Indonesia No. 11 Tahun 2011 Tentang Kesejahteraan Sosial

Riyandno, Muhammad Nafik H. 2010. Rasionalitas Konsumsi Muslim. Program Studi Ekonomi Islam, Fakultas Ekonomi Universitas
Airlangga, disampaikan pada kuliah Seminar Ekonomi Islam.

Spradley, James P. 1997. Metode Etnografi. Terjemahan oleh Misbah Zulfa Tasmara, Toto. 2002. Membudayakan Etos Kerja Islami. Jakarta. Gema Insani. Widiastuti, Tika. 2008, "Dampak korupsi terhadap tingkat kesejahteraan masyarakat di beberapa negara muslim". Tesis tidak diterbitkan. Program Pasca Sarjana Universitas Indonesia.

Widjaja, A.W. 2006. Administrasi Kepegawaian. Jakarta. Rajawali Zadjuli, Suroso Imam. 2008. Prinsip-prinsip Ekonomi Islam. Surabaya: FE Unair 